\section{Food safety in collective catering: knowledge, attitudes and correct application of GHP/GMP knowledge among foodservice workers}

\author{
Chiara Disanto, ${ }^{1}$ Giuseppe Celano, ${ }^{2}$ \\ Angela Dambrosio, ${ }^{3}$ Nicoletta Cristiana \\ Quaglia, ${ }^{3}$ Giancarlo Bozzo, ${ }^{1}$ \\ Antonio Tritto, ${ }^{4}$ Gaetano Vitale Celano ${ }^{1}$ \\ ${ }^{1}$ Department of Veterinary Medicine; \\ ${ }^{2}$ Department of Soil, Plant and Food \\ Science; ${ }^{3}$ Department of Emergency and \\ Organ transplants, University of Bari \\ Aldo Moro; ${ }^{4}$ Agency for the Right to \\ University Study of Apulia Region, \\ ADISU Bari, Italy
}

\begin{abstract}
Food safety critically reliant on the behaviors adopted by foodservice personnel, involved in various stages of meal preparation, from the supply of raw food materials until its distribution to the consumer. The purpose of this work was to collect information on the level of knowledge on food safety, the correct application of the Good Hygiene Practices (GHP) and Good Manufacturing Practices (GMP) and the attitudes of the operators involved in collective catering. The survey was conducted among 15 social catering companies in Apulia (Italy) using a modified Sharif and Al-Malki (2010) anonymous questionnaire intended to assess the knowledge, attitudes and practices of the food handlers. The results highlight the need to improve both knowledge and practices regarding food hygiene and safety in order to minimize the risk of transmitting foodborne diseases. More careful planning, implementation, monitoring and evaluation of training programs for foodservice workers is required, taking into consideration the provisions of European food laws.
\end{abstract}

\section{Introduction}

The typological characteristics of restaurants and catering business have constantly evolving in response to the changes in social needs, lifestyles and technological innovations (Ünlüönen and Cömert,2013). The term "collective catering" refers to a type of catering that serves a large number of people, who are united by their use of a common service, such as the workers of a company, students, soldiers of a barracks and hospital patients (Sharif et al., 2013). This sector has developed rapidly and undergone extensive changes over time. However, these changes have not always been accompanied by equal improvements in terms of food safety, as shown by Chapman et al. (2010). In particular, meals prepared outside of the home represent a risk factor for foodborne illnesses and have been implicated in up to $70 \%$ of outbreaks of foodborne disease in Europe. The collective catering industry, is directly subject to the application of good practice guides $(\mathrm{Ko}, 2013)$. In the past, risk management, in canteens, was limited to the monitoring of the prepared meal, whereas current national and international regulations cover the entire food production process, from the procurement of raw food materials to the food administration phase (Kizen and Guner, 2018). Therefore, the restaurant and catering business must comply with the general hygiene requirements and assume the obligation to implement and maintain permanent procedures based on Hazard Analysis and Critical Control Point (HACCP) principles (Gomes et al., 2013). In accordance with the current legislation, the systematic application of HACCP by catering services would serve to guarantee safe food preparation via the adoption of precautionary measures, identification of risks during the production process and establishment of preventative strategies (Garayoia et al., 2012). However, in order to ensure effective implementation of HACCP, there are several prerequisites (Oliveira et al., 2016), such as a documented system that describes good hygiene practices (GHP) and good manufacturing practices (GMP) required for effective management of food safety (Oliveira et al., 2016). In order to achieve this goal, training programs are needed for collective catering Food Business Operators (FBO) that are relevant to their specific roles in the food production process. The need for an appropriate attitudes related to hygiene among foodservice workers has been highlighted by the decision of the World Health Organization (WHO,1998) No. 785/89 which stated that routine health checks (public health certificate) were not adequate for the prevention of foodborne diseases, and that suitable training and continuous updating the knowledge and skills of catering operators with the in regard to the use of appropriate technologies is more useful (Webb and Morancie, 2015). In addition to the knowledge acquired during the course, a focus on good hygiene practices is fostered: however, this is dependent on the workers' level of education, living and working environment, and personal interest
Correspondence: Chiara Disanto, Department of Veterinary Medicine, University of Bari Aldo Moro, Italy.

E-mail: chiara.disanto@uniba.it

Key words: Food safety; collective catering; good hygiene practices; good manufacturing practices; survey.

Contributions: The authors contributed equally

Conflict of interest: The authors declare no potential conflict of interest.

Funding: None.

Received for publication: 29 July 2019:

Revision received: 12 March 2020.

Accepted for publication: 18 March 2020

This work is licensed under a Creative Commons Attribution-NonCommercial 4.0 International License (CC BY-NC 4.0).

(C) Copyright: the Author(s), 2020

Licensee PAGEPress, Italy

Italian Journal of Food Safety 2020; 9:8453

doi:10.4081/ijfs.2020.8453

in updating their level of professional competence. Surveillance systems have shown that the incidence of Foodborne Diseases (FBD) is almost never associated with the health status of foodservice workers ( $0.6 \%$ of cases) but it is, however, associated with procurement, preparation, storage and administration of food (Merican, 2017). Cross-contamination, lack of personal hygiene, food handling errors, and failure to consider the time-temperature combination during cooking, cooling and heating of foods are the most common mistakes made by foodservice workers (Osaili et al., 2013). The purpose of this study was to collect information on the level of food safety knowledge, correct application of Good Hygiene Practices (GHP) and Good Manufacturing Practices (GMP) and the attitudes of operators involved in collective catering.

\section{Materials and Methods}

The survey was conducted among 15 collective catering companies in Apulia through the administration of an anonymous questionnaire. To select kitchens to be surveyed for the study, we contacted the main collective catering companies located in different provinces in Apulia (Italy). A letter explaining the purpose of the study and requesting cooperation was sent to each company. The contacted companies which 
produce over 25 million meals annually and employs approximately 4,000 people, supply meals to schools, universities, hospitals, state ministries, police forces, armed forces, and public authorities. In addition, the confidentiality of the information gathered was ensured. A modified Sharif and AlMalki (2010) questionnaire for assessing the knowledge, attitudes and practices of the foodservice workers was used. The questionnaire consisted of an initial set of general questions (age, gender, educational level, experience in the sector, current position in the company) followed by 39 questions that were divided into three main sections. Part one included 11 questions about knowledge on food safety with true or false answers, part two included 17 questions about GHP and GMP with "yes or no" answers and part three included 11 questions about related to the attitudes of the food handlers towards food safety.

The time required for completing the questionnaire was 20 minutes. The visits to the kitchens were conducted when the food handlers were undertaking their daily tasks.

\section{Results and Discussion}

\section{General Part}

Among the 156 employees who participated in the survey, $52 \%$ were female
(Figure 1A). The answers to the first section indicated that the respondents had an average age of between 40 and 50 years (33\% of respondents) (Figure 1B) and the possession of a high school diploma (58\%) (Figure 1C). The results revealed there was a weak and indirect association between the length of employment in the foodservice industry and food safety knowledge indicating that persons who had been employed for a longer period had higher levels of food safety knowledge than those with employees with shorter length of experience. These findings contradict those of Webb and Morancie (2015) who stated that employees with longer service had lower levels of food safety knowledge than employees with shorter experience but confirm those of Brannon et al. (2009) and Johnson et al. (2003). No difference in food safety knowledge was observed between employees in various roles. Most operators (33\%) also declared to have gained work experience in the sector over 10 years (Figure 1D). The positions occupied by the participants in the study were as follows: 84 food handlers, 48 cooks, 24 other roles. The observations made during the visits showed that in almost all the kitchens the operators wore the appropriate protective clothing and Personal Protective Equipment (PPE), even if the following deficiencies were detected: presence of jewelry $(60 \%)$ and absence of masks $(50 \%)$.

\section{First section - food safety knowledge}

Based on their answers to questions in the section on food safety knowledge, operators seem to be aware that environmental temperatures, storage temperatures and handling of raw and cooked foods affect the safety of the prepared food. Correct answers were given to questions related to staff hygiene, such as wearing clean and appropriate uniforms, removing jewelry from the hands, applying protections in case of wounds/cuts to the hands. However, results indicated that $8 \%$ of the operators lacked appropriate knowledge of food storage temperatures (Table 1). This result contradicts previous findings that the knowledge of critical temperatures among their study participants is high (Barjaktarovic-Labovic et al., 2018). The lack of knowledge regarding temperature control among food handlers reported in some studies in Italy (Buccheri et al., 2007; Marais et al., 2007; Panchal et al., 2011) is very similar to the present results. Poor cleaning practices represent the main ineffectiveness of utilizing hazards and problems of monitoring temperatures (especially at thermal treatment) and crosscontamination (Walker and Jones, 2002). HACCP implementation in small and medium-sized food businesses in the UK focused on temperature control and the data showed poor results (60\%) (Walker et al., 2003). Almost all the operators (94\%) agreed
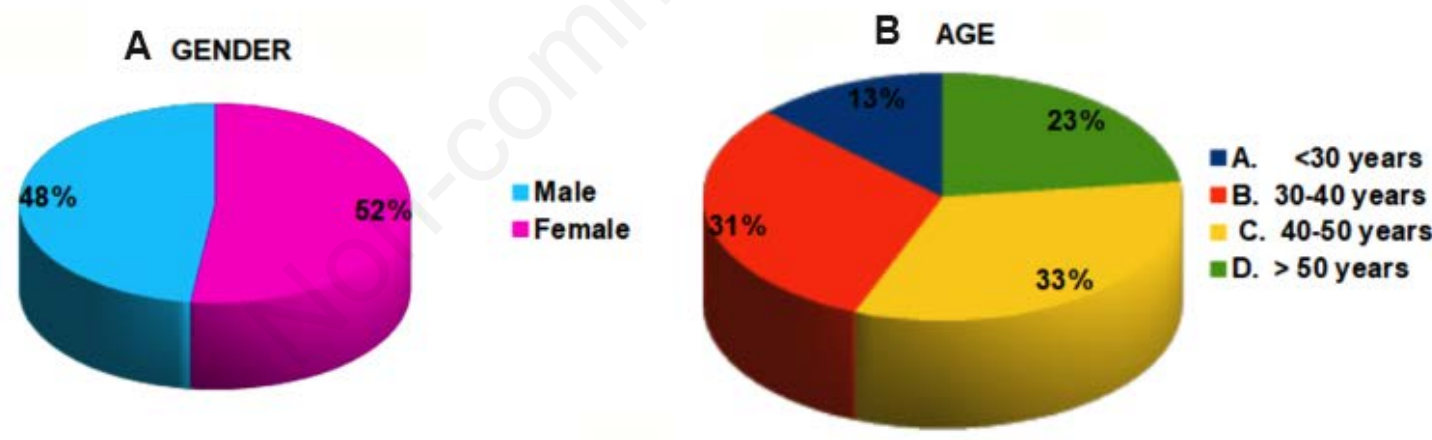

C educational level

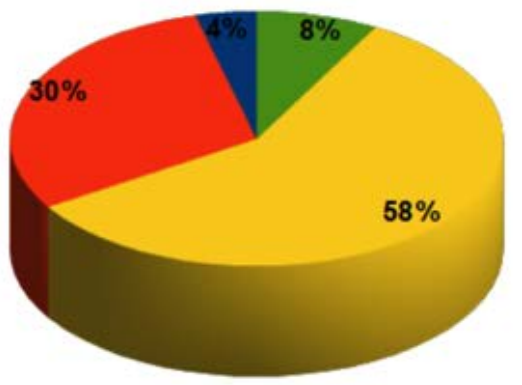

D YEARS OF EXPERIENCE IN THE SECTOR
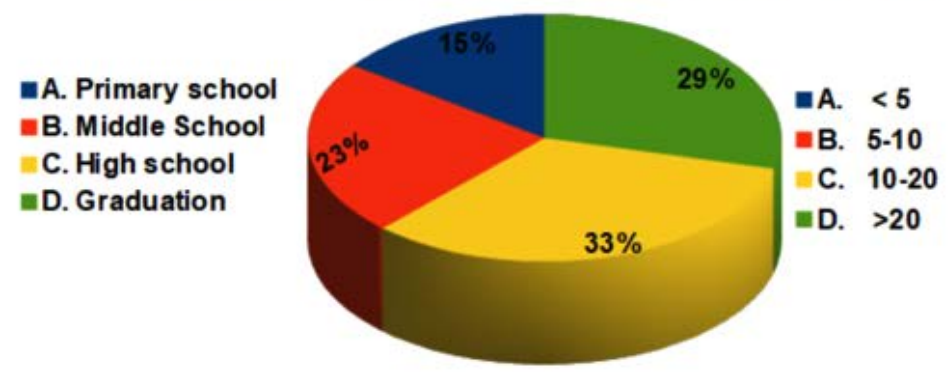

Figure 1 . General part. A) Gender; B) Age; C) Educational level; D) years of experience in the sector. 
on the need necessity to keep cooked foods separate from raw ones (Table 1) indicating a good understanding of the crosscontamination. Cross-contamination, which refers to the transfer of pathogenic microorganisms from contaminated (usually raw) foods to other non-contaminated (usually cooked) foods can occur under various when the same kitchen utensils are used for the handling of raw and cooked foods, without replacing or washing and disinfecting them between uses or during the handling of cooked foods, that are ready for consumption, without a appropriate hand washing (Sharif et al., 2015). Therefore, because cross-contamination is the most widespread form of food contamination, it is essential that foodservice workers have a basic knowledge of GMP and GHP principles and, importantly, awareness of putting these principles into practice. In question n.10, we asked to the foodservice workers if the failure by operators to adopt good hygiene practices could cause food contamination. As shown in Table 1 this information has been preserved, over time, by almost all operators. Foodservice workers recognize the importance of adequate GHP and GMP procedures to reduce the risk of food contamination and consider it important to wash their hands before handling foodstuffs. In their answers to question n.11 almost all participants in our survey indicate that they are aware of the risks due to repeated heating of food, before consumption. Ready-to-eat foods must be adequate adequately heated, to ensure that entire volume of the food product reaches the pasteurization temperature $\left(>72^{\circ} \mathrm{C}\right.$ for a few minutes). The true answers given to question 4 are questionable: "Do knives and cutting boards only need to be washed at the end of each working day?". If the cleaning of tools and of work surfaces was carried out only at the end of the working day, this would result in the accumulation of food residues and dirt on the equipment and promote the growth of microrganisms.

\section{Second section - application of Good Hygiene Practices and Good Manufacturing Practices}

In the second section of the questionnaire, the operators confirm their knowledge of the methods of application of the HACCP system, and that they follow their own food self-control plans. Operators appeared to be aware that environmental temperatures, storage temperatures, and handling of raw and cooked foods affect the safety of the preparations prepared foods. Further, $96 \%$ of the respondents understood that the HACCP system is aimed at food safety (Table 2). Almost all of the respondents (98\% and 94\%) agreed the knowledge and control of the refrigerator and freezer temperatures (question No. 25) and incorrect management and handling of food (question no. 24) play an important role

Table 1. Responses to the questionnaire "Knowledge on food safety".

$1 \quad$ Foodborne diseases are caused by pathogenic microorganisms

$2 \quad$ Should operators with infected cuts on their fingers apply protection and avoid touching food?

$3 \quad$ Food handlers must wear clean and appropriate uniforms, remove jewelry from hands

$4 \quad$ Do knives and cutting boards need to be washed only at the end of each working day?

5 The correct refrigeration temperature is below $10^{\circ} \mathrm{C}$

$6 \quad$ Packaged raw foods can be placed directly on the floor

$7 \quad$ Mixing raw and cooked foods increases the risk of cross-contamination

94

8 Eating raw or undercooked meat could cause foodborne diseases

$9 \quad$ Eating raw unwashed vegetables could cause foodborne diseases

10 Food handlers who do not adopt good hygiene practices could be a cause of food contamination

11 Can reheating foods increase the risk of food contamination?

Table 2. Responses to the questionnaire "Good hygiene practices and good manufacturing practices".

\begin{tabular}{lll}
12 & Do you know about what HACCP means? & 94 \\
\hline 13 & Do you think that the prerequisites for HACCP are necessary? & 96 \\
\hline 14 & Do you respect the objectives of the HACCP plan? & 98 \\
\hline 15 & Does the HACCP system prefer prevention to inspection? & 87 \\
\hline 17 & The HACCP system is a method to ensure food safety & 96 \\
\hline 18 & The HACCP system applies to the quality of the final product and not to the preparation procedures \\
19 & Do you usually follow the HACCP plan to ensure food safety? & 23 \\
\hline 20 & Do you have practical difficulties in carrying out the provisions of food self-control manual? \\
21 & Do you maintain adequate levels of food hygiene during the various phases of food preparation? \\
\hline 22 & Do you have informations on your suppliers and carry out checks on incoming raw materials? \\
23 & Do you record operations during your daily work? & 96 \\
\hline 24 & The correct management and hygienic handling of food is part of your job responsibilities \\
25 & Is it important to check the temperature of the refrigerator to prevent foodborne diseases? & 98 \\
\hline 26 & Vegetables and fruit must be washed thoroughly to prevent the risk of foodborne diseases \\
27 & Raw vegetables and meat should not be cut using the same knife & 90 \\
\hline
\end{tabular}


in the prevention of foodborne diseases (Table 2). Our results indicated that $85 \%$ of food handlers knew that raw vegetables and meat should not be cut using the same knife (question no. 27). Our findings were similar to those of a Slovenian study (Jevsnik et al., 2008). In question n.28 we asked if hand washing, before handling food, could reduce the possibility of contamination of the foods. Table 2 clearly shows how this information has been preserved over time by most operators (73\%). In Manning and Snider's study (1993), most respondents recognized the importance of washing their hands before handling food materials. However, a significant proportion of operators $(27 \%)$ did not believe that washing hands before handling food materials increases the risk of food contamination, leads to consider this as a consequence of the task performed. It is possible that these respondents haven't do not fully understand the consequences of their actions, suggesting that further training may be valuable in their case. Overall, different results were found in relation to HACCP documentation and HACCP practice. Responses indicated that the participants were better at documenting HACCP principles than implementing them practically, which adversely affected food safety (Trafialek and Kolanowski, 2014). In order to be effective, HACCP practices must be underpinned by knowledge and skills of both management and staff (Fletcher et al. 2009). A lack of knowledge in this area is well documented (Rebouças et al., 2017; Sibanyoni and Tabit, 2017). Effective food safety systems are reliant on adequate funds, support from management, and dedicated food preparation consultants. In this way the common resistance of staff to the implementation (Garayoa et al., 2011; Sibanyoni and Tabit, 2017).

\section{Third section - attitudes towards food safety}

Despite the skepticism of some operators toward completing the questionnaire, the attitudes towards food security as a whole were positive among all the operators interviewed, respondents showed an interest in deepening their knowledge of food safety through reading newspaper articles, enrolling on training courses, and attending seminars and discussions with consultants of the food self control. Furthermore all respondents agreed that the use of gloves and adequate protective clothing (question n.34) play an important role in the prevention of foodborne diseases (Table 3). All food handlers surveyed considered that monitoring the fridge/freezer temperatures was important in order to reduce the risk of food spoilage. In two different studies, results indicated that the respondents' knowledge about of food freezing varied. Among the participants, 57\% believed that microbial growth arrested at temperatures below $-18^{\circ} \mathrm{C}$ while $21 \%$ consider that freezing kills all bacteria (Walker and Jones, 2002).

\section{Conclusions}

The results of the present study highlight the urgent need to remodel food safety education and training systems to include regular workshops and training sessions. In this setting, participants will receive handson experience in measures to reduce contamination, they would be trained to correctly read and interpret measurements (e.g., using food thermometers), and receive guidance on appropriate cleaning and sanitation measures. The present results indicate that training programs should be accompanied by practical experience that is as relevant as possible to the working context and actual tasks carried out. The improvement of food safety standards throughout the food service industry is strongly affected by social, economic and environmental factors. The lack of, or insufficient, adoption of good hygiene practices by foodservice workers may not always result from ignorance, but also arise as a consequence of "external" circumstances (Martins et al., 2014). Therefore, appropriate management of food service staff is critical: a positive and motivational atmosphere in the workplace contributes significantly to greater productivity and general improvement in the application of HACCP procedures. Furthermore, managers must set the right example by practicing correct food safety measures during operations. They should also educate employees on food safety policies and management systems, such as HACCP in order to encourage employees to practice safe food handling from a conscious rather than instructive stand point. Finally, this study revealed moderate level of knowledge and practice among the foodservice employees indicating the need for stronger regulations in relation to training, legislation, and certification, as well as continuous assessment for retaining food badges. Moreover, awareness programs aimed at improving food safety knowledge are critical for foodservice employees. The present findings may additionally be used by public health officials and foodservice professionals to plan, evaluate, and modify food safety education programs in order to increase food safety knowledge and improve food handling practices across the food industry.

Table 3. Responses to the questionnaire "Attitude towards food safety".

\begin{tabular}{lll}
\hline Attitude towards food safety & Yes/no \% & \% \\
29 & Do you know the current food safety legislation? & 79 \\
30 & Would you read more newspapers about food safety to increase your knowledge about food hygiene? & 98 \\
\hline 31 & Do you attend training courses or consult your food self-control consultants to keep up to date on food safety? & 88 \\
32 & Do you think that attending a seminar on food hygiene could improve your behavior in this area? & 98 \\
\hline 33 & Are food handlers responsible for preventing food borne diseases? & 98 \\
34 & The use of headgear, mask, protective gloves and adequate clothing reduces the risk of food contamination & 100 \\
35 & It is important to know the temperature of the fridge / freezer to reduce the risk of food spoilage & 100 \\
36 & Do operators need to undergo periodic health checks? & 100 \\
\hline 37 & Do you think keeping the kitchen clean is a good way to control food safety? & 100 \\
\hline 38 & Is the application of food self-control system important for restaurants and institutions? & 98 \\
\hline 39 & Do you think that food safety is a prerequisite? & \\
\hline
\end{tabular}




\section{References}

Barjaktarovic-Labovic S, Mugoša B, Andrejević V, Banjari Ines, Jovićević L, Djurovic D, Martinovic A, Radojlović J, 2017. Food hygiene awareness and practices before and after intervention in food services in Montenegro. Food Control 85.

Brannon LA, York VK, Roberts KR, Shanklin CW, Howells AD, 2009. Appreciation of food safety practices based on level of experience. J Foodservice Bus Res 12:134e154.

Buccheri C, Casuccio A, Giammanco S, Giammanco M, La Guardia M, Mammina C, 2007. Food safety in hospital: Knowledge, attitudes and practices of nursing staff of two hospitals in Sicily, Italy. BMC Health Serv Res $3: 45$.

Chapman B, Eversley T, Fillion K, MacLaurin T, Powell D, 2010. Assessment of Food Safety Practices of Food Service Food Handlers (Risk Assessment Data): Testing a Communication Intervention (Evaluation of Tools). J Food Protect 73.1101-7.

Fletcher SM, Maharaj SR, James K, 2009. Description of the food safety system in hotels and how it compares with HACCP standards. J Travel Med 16:3541.

Garayoa R, Vitas A, Díez-Leturia M, GarcíaJalón I, 2011. Food safety and the contract catering companies: Food handlers, facilities and HACCP evaluation. Food Control 22:2006-12.

Gomes N, Araujo AC, Ramos E, Cardoso CS, 2013. Food handling: comparative analysis of general knowledge and practice in three relevant groups in Portugal. Food Control 18:707-12

Jevsnik M, Hlebec V, Raspor P, 2008. Food safety knowledge and practices among food handlers in Slovenia. Food Control 19:1107e1118.

Johnson L, Shin JH, Feinstein AH, Mayer KJ, 2003. Validating a food safety instrument: measuring food safety knowledge and attitudes of restaurant employees. J Foodservice Bus Res 6:49e65

Kizen A, Güner A, 2018. Investigation of Compliance on Good Manufacturing Practices (GMP) and Hygiene Conditions in Enterprises That Supply Mass Catering Services. Int J Food Engin Res 4:25-36.

Ko WH, 2013. The relationship among food safety knowledge, attitudes and selfreported HACCP practices in restaurant employees. Food Control 29:192-7.

Manning CK, Snider OS, 1993. Temporary public eating places: food safety knowledge, attitudes and practices. $\mathrm{J}$ Environ Health 56:24e28.

Marais M, Conradie N, Labadarios D, 2007. Small and micro enterprises e aspects of knowledge, attitudes and practices of managers' and food handlers' knowledge of food safety in the proximity of Tygerberg Academic Hospital, Western Cape. South Afr J Clin Nutr 20:50e61.

Martins RB, Ferreira D, Moreira LM, Hogg T, Gestal J, 2014. Knowledge on food hygiene of food service staff working in nursing homes and kindergartens in Porto region - Portugal. Food Control 42:54-62.

Merican Z, 2017. GMP and HACCP: are you confused? Paper Presented at Symposium on Current and Innovative Approaches to Microbiological Food Safety Managment organized by ICMSF, ILSI-SEAR, AVA. Singapore, October 3-4, 2017

Oliveira CA, Cruz F, Tavolaro P, Corassin $\mathrm{CH}$, 2016. Food Safety: Good Manufacturing Practices (GMP), Sanitation Standard Operating Procedures (SSOP), Hazard Analysis and Critical Control Point (HACCP). Chapter 10. In: Antimicrobial Food Packaging, 129-139.

Osaili TM, Abu-Jamous DO, Obeidat BA, Bawadi HA, Tayyem RF, Subih HS, 2013. Food safety knowledge among food workers in restaurants in Jordan. Food Control 31:145-50.

Panchal KP, Carli A, Dworkin SM, 2011. Identifying food safety knowledge gaps among restaurant food handlers in
Bolzano, Italy. Food Protection Trends 34:83e93.

Rebouças LT, Santiago LB, Martins LS, Rios Menezes AC, Purificaçao Nazare Araújo M, De Castro Almeida RC, 2017. Food safety knowledge and practices of food handlers, head chefs and managers in hotel's restaurants of Salvador, Brasil. Food Control 73:372

Sharif L, Al-Malki T, 2010. Knowledge, Attitude and Practice of Taif University Students on Food Poisoning. Food Control 21:55-60.

Sharif L, Obaidat M, Al-Dalalah MR, 2013. Food Hygiene Knowledge, Attitudes and Practices of the Food Handlers in the Military Hospitals. Food Nutr Sci 4:24551.

Sibanyoni JJ, Tabit FT, 2017. Assessing the food safety attitudes and awareness of managers of school feeding programmes in Mpumalanga, South Africa. J Comm Health 42:664-73.

Trafialek J, Kolanowski W, 2014. Application of failure mode and effect analysis (FMEA) for audit of HACCP system. Food Control 44:35-44.

Ünlüönen K, Cömert M, 2013. Identifying personnel hygiene knowledge levels of kitchen staff in hotel establishments. J Tourism Gastron Stud 1:3-12.

Walker E, Jones N, 2002. An assessment of the value of documenting food safety in small and less developed catering businesses. Food Control 13:307e314.

Walker E, Pritchard C, Foorsythe S, 2003. Hazard analysis critical control point and prerequisite programme implementation in small and medium size food businesses. Food Control 14:169e174.

Webb M, Morancie A, 2015. Food safety knowledge of foodservice workers at a university campus by education level, experience, and food safety training. Food Control 50:259-64.

World Health Organization, 1998. Guidance on regulatory of HACCP report of joinFAO/WHO Consultation on the role of government agencies in assessing HACCP. Geneva 2-6 June 1998 WHO/FSF/FOS/98.5. 